\title{
ERODIBILIDADE, FATORES COBERTURA E MANEJO E PRÁTICAS CONSERVACIONISTAS EM ARGISSOLO VERMELHO-AMARELO, SOB CONDIÇÕES DE CHUVA NATURAL ${ }^{(1)}$
}

\author{
Eliete Nazaré Eduardo ${ }^{(2)}$, Daniel Fonseca de Carvalho ${ }^{(3)}$, Roriz Luciano Machado $^{(4)}$, Paula \\ Fernanda Chaves Soares ${ }^{(5)}$ \& Wilk Sampaio de Almeida ${ }^{(6)}$
}

\begin{abstract}
RESUMO
Os modelos de predição de perda de solo têm se tornado importantes ferramentas no planejamento conservacionista, sendo, para tanto, fundamental a estimativa local dos parâmetros que influenciam o processo erosivo. $O$ objetivo deste trabalho foi determinar a erodibilidade (fator $\mathrm{K}$ ) e os fatores manejo e cobertura (fator $\mathrm{C}$ ) e práticas conservacionistas de suporte (fator $\mathrm{P}$ ) da Equação Universal da Perda de Solo (USLE), em um Argissolo Vermelho-Amarelo. Foram avaliadas as perdas de solo (PS) ocorridas em parcelas-padrão de Wischmeier, no período de 2006 a 2011, com seus respectivos índices de erosividade $\left(\mathrm{EI}_{30}\right)$. Valores de erodibilidade foram calculados pelo quociente entre $P S$ e $\mathrm{EI}_{30}$ das chuvas anuais (Ka) e total no período (Kt) e pelo coeficiente angular gerado pela análise de regressão linear entre esses mesmos parâmetros (Kci e Kct). Os fatores C e P foram estimados para a cultura do milho, durante três anos de cultivo em nível (MN). Os valores de Kt e Kct obtidos foram de 0,0090 e 0,0106 $\mathrm{Mg} \mathrm{ha} \mathrm{h} \mathrm{ha}^{-1} \mathrm{MJ}^{-1} \mathrm{~mm}^{-1}$, respectivamente. Os valores médios calculados para os fatores $C$ e $P$ são de

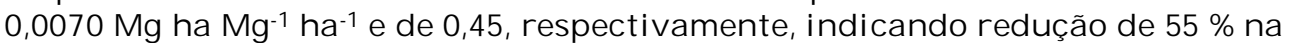
perda de solo do $\mathrm{MN}$, em relação ao MMA. Os valores dos fatores $\mathrm{K}, \mathrm{C}$ e $\mathrm{P}$ encontrados podem ser usados como primeira aproximação para estudos de manejo e conservação do solo e da água na região.
\end{abstract}

Termos de indexação: erosão hídrica, USLE, fator K, fator C, fator $P$.

\footnotetext{
(1) Parte da Dissertação de Mestrado do primeiro autor apresentada ao Curso de Pós-Graduação em Agronomia - Ciência do Solo, Universidade Federal Rural do Rio de Janeiro - UFRRJ. Recebido para publicação em 30 de outubro de 2012 e aprovado em 5 de abril de 2013.

(2) Doutoranda em Ciência do Solo, UFLA. E-mail: elietenazare@gmail.com

(3) Professor Associado IV do Departamento de Engenharia, UFRRJ. Bolsista do CNPq. E-mail: carvalho@ufrrj.br

(4) Professor, Instituto Federal de Educação, Ciência e Tecnologia Goiano - Câmpus Ceres. Rod. 154, km 03. Caixa Postal 51. CEP 76300-000 Ceres (GO). E-mail: roriz.machado@ifgoiano.edu.br.

(5) Doutoranda em Agronomia - Ciência do Solo, UFRRJ. E-mail: pfernanda07@gmail.com

(6) Mestrando em Agronomia - Ciência do Solo, UFRRJ. E-mail: wilk434@gmail.com
} 


\title{
SUMMARY: ERODIBILITY, SOIL COVER AND MANAGEMENT AND CONSERVATION PRACTICES IN RAINFED ULTISOL
}

\begin{abstract}
The soil loss prediction models have become important tools for conservation planning, being fundamental the local estimation of the parameters that influence the erosion processes. The objective of this work was to determine the soil erodibility ( $K$ factor), soil cover and management factor ( $C$ factor) and conservation practice factor ( $P$ factor) of the Universal Soil Erosion Equation (USLE), in an Ultisol. Soil losses (SL) were measured in Wischmeier standardplots from 2006 to 2011, with the respective erosivity index $\left(E I_{30}\right)$. Soil erodibility was calculated by the ratio of $S L$ and the annual $(K a)$ and total period $E I_{30}(K t)$, considering the angular coefficient generated from the linear regression analysis between those parameters (Kci, for each rainy period, and $K c t$, for the studied period). The factors $C$ and $P$ were estimated for three years of maize in contour cultivation (MCL) and down in the slope (MDS). The Kt and Kct

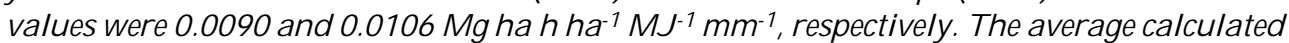
values for factors $C$ and $P$ are $0.0070 \mathrm{Mg} \mathrm{ha} \mathrm{Mg-1}^{-1} \mathrm{ha}^{-1}$ and 0.45 , respectively, indicating a soil loss reduction of $55 \%$ in $M C L$, compared to $M D S$. The values of the factors $K, C$ and $P$ obtained can be used as first approximation to soil and water conservation management projects in the region.
\end{abstract}

Index terms: water erosion, USLE, K factor, C factor, $P$ factor.

\section{INTRODUÇÃO}

A degradação dos solos é um problema que influencia todo o mundo e constitui um fenômeno de grande importância, em razão da rapidez com que se processa e pelo fato de acarretar grandes prejuízos para diversas atividades econômicas e para o meio ambiente. Segundo Bertoni \& Lombardi Neto (2010), a erosão hídrica é a forma mais ativa do processo de degradação dos solos.

O objetivo da maior parte das pesquisas sobre erosão é medir a influência dos diferentes fatores determinantes no processo, a fim de possibilitar estimativa de perdas de solo e selecionar práticas que as reduzam ao máximo. Para a avaliação e predição das perdas de solo por erosão, a Equação Universal de Perda de Solo (USLE), apresentada por Wischmeier \& Smith (1978), tem sido o modelo mais utilizado em todo o mundo (Kinnell, 2010). Essa equação engloba um conjunto de fatores como a erosividade da chuva (R), a erodibilidade do solo (K), a topografia (LS), o uso e manejo do solo (C) e as práticas conservacionistas de suporte $(\mathrm{P})$.

A erodibilidade representa a suscetibilidade do solo ao processo erosivo e pode ser determinada de forma direta, pela razão entre as perdas de solo e a erosividade das chuvas, sob chuva natural ou chuva simulada, e também por meio de análise de regressão linear simples entre essas duas variáveis (Wischmeier \& Smith, 1978). De forma indireta, a erodibilidade pode ser estimada por meio da representação gráfica (nomograma),com base na combinação dos atributos físicos dos solos (textura, estrutura e permeabilidade), com porcentagem de matéria orgânica (Wischmeier et al., 1971). De acordo com Singh \& Khera (2009), o nomograma tem sido amplamente utilizado em todo o mundo, mas diversos estudos têm indicado que o método não é adequado para uso no Brasil (Marques et al., 1997; Silva et al., 2000; Amorim et al., 2009; Eduardo, 2012).

Segundo Pruski (2009a), diferentes tipos de solos no Brasil já apresentam seus valores de erodibilidade determinados, principalmente com uso de simuladores de chuvas. Conforme o levantamento de Denardin (1990), a erodibilidade de solos com horizonte B latossólico varia de 0,002 a $0,034 \mathrm{Mg}$ ha h (ha MJ mm) ${ }^{-1}$ e com horizonte B textural, de 0,004 a 0,044 Mg ha h (ha MJ mm)-1. Silva et al. (2009), na região de Lavras -MG, encontraram valores de erodibilidade de $0,0355 \mathrm{Mg}$ ha h ha-1 $\mathrm{MJ}^{-1} \mathrm{~mm}^{-1}$, para Cambissolo,

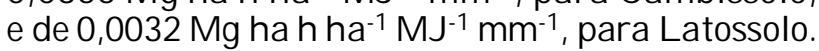
Para Nitossolo Háplico alumínico, Bertol et al. (2007) encontraram valor de fator $\mathrm{K}$ de $0,011 \mathrm{Mg}$ ha h ha-1 $\mathrm{MJ}^{-1} \mathrm{~mm}^{-1}$.

Para determinada cultura, o fator cobertura e manejo do solo representa o somatório dos produtos da razão de perda de solo (RPS) pela fração do índice de erosividade $\left(\mathrm{FEI}_{30}\right)$ de cada estádio da cultura (Wischmeier \& Smith, 1978). Esse fator varia de 0 a 1 , aproximando-se de 0 , nos sistemas de manejo conservacionistas, e de 1 , nos não conservacionistas (Bertol et al., 2002a).

No Brasil, a literatura sobre esse assunto é ainda escassa, sendo, portanto, necessária a execução de pesquisas nos mais diferentes locais por causadas variações existentes e da localização geográfica como a chuva, o solo e a topografia do terreno (Amaral et al., 2008). O método descrito por Wischmeier \& Smith (1978) permite determinar os valores do fator C para rotações de culturas e práticas de manejo encontradas nos EUA. Para outros países, no entanto, as informações detalhadas para o cálculo do fator $\mathrm{C}$ são escassas (Morgan, 2005). 
O fator de práticas conservacionistas de suporte (P), por sua vez, representa o efeito de práticas de conservação do solo como preparo e plantio em contorno (nível) e terraceamento e plantio em faixas em contorno, expressando a relação entre a perda de solo com determinada prática conservacionista e a correspondente perda quando a cultura está implantada no sentido do declive (morro abaixo) (Wischmeier \& Smith, 1978).

Segundo Amorim et al. (2010), uma limitação do uso da USLE no Brasil é a falta de base de dados, visando a determinação precisa dos fatores $\mathrm{C} \mathrm{e} P$ para as condições brasileiras de uso e manejo do solo. Diante do exposto, os objetivos deste trabalho foram determinar o fator erodibilidade de Argissolo Vermelho-Amarelo, sob chuva natural, e calcular os fatores manejo e cobertura do solo e práticas conservacionistas para a cultura de milho.

\section{MATERIAL E MÉTODOS}

O estudo foi realizado sob condições de chuva natural em Argissolo Vermelho-Amarelo, localizado na área experimental da Embrapa-Agrobiologia em Seropédica, RJ. No quadro 1, é apresentada a caracterização do solo em estudo, realizada de acordo com Embrapa (1997).

As avaliações visando à determinação da erodibilidade do solo compreenderam os anos de 2004 a 2011, sendo descartados os períodos chuvosos 20042005 e 2005-2006, pois, segundo Wischmeier \& Smith (1978), os dois primeiros anos de coleta devem ser desconsiderados, a fim de minimizar o efeito da variação das condições de superfície no cálculo da erodibilidade.

A área experimental constituiu-se de três parcelas com dimensões de $22,1 \times 3,5 \mathrm{~m}$, com declividade média de $0,09 \mathrm{~m} \mathrm{~m}^{-1}$, delimitada por chapas galvanizadas e conectadas a reservatórios para coleta de enxurrada (Carvalho et al., 2009). Antes da estação chuvosa, em cada período de avaliação, o solo das parcelas foi preparado de forma convencional (uma aração e duas gradagens), variando o sentido do preparo em razão do tratamento adotado, sendo: preparo convencional do solo em nível e milho (Zea mays L.) cultivado com espaçamento de $1,0 \mathrm{~m}$ entrelinhas e $0,3 \mathrm{~m}$ entre plantas, com as linhas dispostas em nível (MN); preparo convencional do solo e plantio de milho com o mesmo espaçamento, porém com as linhas de plantio dispostas de morro abaixo (MMA); e preparo convencional do solo no sentido do declive, mantendose o solo sem cobertura durante a execução do experimento (SN). Vale ressaltar que a estimativa dos fatores $\mathrm{C}$ e $\mathrm{P}$ foi realizada apenas nos períodos 2007 2008, 2008-2009 e 2010-2011, enquanto a determinação de $\mathrm{K}$ foi avaliada em todo o período de análise.

As avaliações foram realizadas a cada evento erosivo com produção de sedimentos, considerando tanto sedimentos sólidos quanto em suspensão na água escoada para as caixas de coleta, conforme método descrito em Carvalho et al. (2009).

A precipitação pluvial foi registrada em pluviógrafo dotado de datalogger, cujos dados foram sistematizados e processados no programa computacional Chuveros (Programa computacional desenvolvido pelo prof. Elemar Antonino Cassol/UFRGS), para obter a erosividade de cada evento de chuva. $\mathrm{O}$ aplicativo utiliza o método de Wischmeier \& Smith (1978), que calcula a energia cinética da chuva $(\mathrm{E})$ em cada segmento de intensidade uniforme, a partir da equação proposta por Foster et al. (1981) (Equação 1):

$$
\mathrm{E}=0,119+0,0873 \log \mathrm{I}
$$

em que "I" é a intensidade da chuva, em $\mathrm{mm} \mathrm{h}^{-1}$. Os resultados foram multiplicados pela intensidade de chuva correspondente a cada segmento, obtendo-se, após o somatório dos valores, a energia cinética total para cada chuva (Ec). Para obter a erosividade da chuva, o valor Ec foi multiplicado pela máxima lâmina precipitada em $30 \mathrm{~min}\left(\mathrm{I}_{30}\right)$, resultando, finalmente, para cada chuva, no índice de erosividade denominado $\mathrm{EI}_{30}$ (Carvalho et al., 2005).

Com os dados de $\mathrm{EI}_{30}$ e de perdas de solo (Ps) correspondentes, foi determinada a erodibilidade do solo por dois métodos: pelo quociente entre $\mathrm{Ps} \mathrm{e} \mathrm{EI}_{30}$, para cada período chuvoso (Ka) e para todos os anos do estudo (Kt); e considerando o coeficiente angular da curva ajustada por meio de regressão linear simples entre os dados de Ps e de $\mathrm{EI}_{30}$, para cada período chuvoso (Kci) e para todo o período estudado (Kct).

Quadro 1. Características granulométricas do Argissolo Vermelho-Amarelo(1) estudado

\begin{tabular}{ccccccc}
\hline Horizonte & Profundidade & Areia & Silte & Argila total & Grau de floculação & Silte/Argila \\
\hline & $\mathrm{cm}$ & & $\mathrm{g} \mathrm{kg}^{-1}$ & & $\%$ & \\
$\mathrm{nyyyynn}$ & $0-16$ & 580 & 150 & 260 & 27 & 0,59 \\
$\mathrm{AB}$ & $16-27$ & 500 & 140 & 360 & 49 & 0,38 \\
BA & $27-46$ & 430 & 130 & 440 & 44 & 0,30 \\
3Bt & $46-155+$ & 387 & 130 & 483 & 76 & 0,29 \\
\hline
\end{tabular}

(1) Extraído de Carvalho et al. (2009). 
O fator cobertura e manejo do solo (Equação 2) foi obtido em quatro diferentes fases ao longo do ciclo da cultura do milho, tendo cada fase igual tempo de duração (Wischmeier, 1960):

$$
\mathrm{C}=\mathrm{RPS} \mathrm{FEI}_{30}
$$

em que RPS = razão de perda de solo; e FEI $_{30}=$ fração do índice de erosividade $\left(\mathrm{EI}_{30}\right)$, responsável pela perda de solo.

A RPS em cada fase do ciclo das culturas foi calculada pela razão entre a perda de solo ocorrida no tratamento com a cultura do milho e a perda correspondente advinda na parcela-padrão da USLE (Equação 3):

$$
\mathrm{RPS}_{\mathrm{i}}=\frac{\sum_{\mathrm{i}=1}^{\mathrm{n}} \mathrm{PS}_{\mathrm{m}}}{\sum_{\mathrm{i}=1}^{\mathrm{n}} \mathrm{PS}_{\mathrm{d}}}
$$

$\mathrm{AFEI}_{30}$ em cada fase do ciclo das culturas foi obtida pela razão entre o valor da erosividade que causou a perda de solo em cada uma das fases no ciclo das culturas e o valor total da erosividade ocorrida no ciclo da cultura do milho (Equação 4):

$$
\mathrm{FEI}_{30}=\frac{\sum_{\mathrm{i}=1}^{\mathrm{n}} \mathrm{R}_{\mathrm{i}}}{\mathrm{R}}
$$

O somatório dos valores do fator $\mathrm{C}$ ao longo do ciclo das culturas permitiu a obtenção deste fator, sob os diferentes manejos do solo.

$\mathrm{O}$ fator $\mathrm{P}$, conseguido nas mesmas fases de obtenção do fator $\mathrm{C}$, foi determinado pela relação entre as perdas de solo verificadas nos tratamentos cultivados com milho em nível e o plantio morro abaixo, respectivamente (Equação 5):

$$
\mathrm{P}=\frac{\mathrm{PSmn}}{\mathrm{PS} m \mathrm{a}}
$$

em que PSmn = perda de solo na parcela cultivada com milho em nível; e PSma = perda de solo na parcela cultivada com milho morro abaixo.

\section{RESULTADOS E DISCUSSÃO}

Os índices de erodibilidade calculados (Ka e Kt) e os estimados (Kci e Kct) para a área de estudo são apresentados no quadro 2. Conforme se observa, os índices apresentaram alta variabilidade entre os anos avaliados.

A variabilidade observada nos valores de erodibilidade pode estar relacionada às variações climáticas que influenciam no potencial erosivo das chuvas (Bertol et al., 2007), uma vez que a precipitação pluvial natural é variável, espacial e temporalmente
(Frauenfeld \& Truman, 2004). Segundo Singh \& Khera (2009), mudanças no teor de matéria orgânica do solo, agregação e características de infiltração podem influenciar na erodibilidade. Além dessas variáveis, fatores como a umidade antecedente no momento dos picos de maior intensidade, precisão na quantificação dos sedimentos sólidos e em suspensão e mobilização do solo por meio de prática de capina antes de chuva de alta erosividade também influenciam os resultados.

$O$ valor de erodibilidade estimado por regressão linear simples, para todo o período (Kct), foi 15,1\% superior ao calculado pela razão entre as perdas de solo e a erosividade das chuvas (Kt). Bertol et al. (2007), ao estudarem um Nitossolo Háplico alumínico, em Santa Catarina, encontraram valor estimado de $9 \%$ superior ao calculado.

A erodibilidade obtida por meio de regressão linear simples (Kc) apresentou valores de coeficiente de determinação próximos entre si e em torno de 0,70 , com exceção do período 2009/2010. Por sua vez, o Kct que compreende a regressão dos dados de todo o período avaliado apresentou $R^{2}=0,39$, conforme figura 1 .

Apesar da dispersão dos pontos, comportamento normal em estudos dessa natureza, a correlação das variáveis perda de solo e a da erosividade das chuvas se apresentaram estatisticamente significativas, comprovando o grau de associação entre ambas.

Para a mesma classe de solo, Marques et al. (1997) obtiveram para a região de Sete Lagoas - MG, sob chuva natural, fator $\mathrm{K}$ de $0,033 \mathrm{Mg}$ ha h ha-1 $\mathrm{MJ}^{-1}$ $\mathrm{mm}^{-1}$, praticamente três vezes maior ao encontrado para o Argissolo estudado. Entretanto, os índices de erodibilidade apresentados para o solo em questão foram muito semelhantes aos obtidos por Bertol et al. (2002b) para Cambissolo Húmico, os quais encontraram valores de $0,0105 \mathrm{Mg}$ ha $\mathrm{h} \mathrm{ha}^{-1} \mathrm{MJ}^{-1} \mathrm{~mm}^{-1}$, para o período primavera-verão, e $0,021 \mathrm{Mg}$ ha h ha ${ }^{-1}$ $\mathrm{MJ}^{-1} \mathrm{~mm}^{-1}$, para as mesmas estações do ano, pelo método da regressão.

Os valores de perdas de solo, fração do $\mathrm{EI}_{30}$, razão de perdas de solo e fator $\mathrm{C}$, nas diferentes fases do ciclo da cultura de milho, sob dois sistemas de manejo, são apresentados no quadro 3. Os estádios foram divididos em períodos de aproximadamente 30 dias. Não foi possível avaliar o período antes do plantio,em razão da sua proximidade com o preparo do solo.

Analisando o quadro 3, observou-se que os valores do fator $\mathrm{C}$ variaram consideravelmente ao longo das fases, em virtude do desenvolvimento da cultura ao longo do tempo. No início do ciclo, a cultura apresenta uma fase de desenvolvimento mais lenta, influenciando nos maiores valores para $\mathrm{o}$ fator $\mathrm{C}$ (menor cobertura do solo). Além disso, o período correspondente à primeira fase do ciclo da cultura normalmente coincide com o início do período chuvoso na região, quando o solo está recém-preparado e ainda praticamente exposto. Em seguida, a cultura estabiliza seu crescimento, promovendo a interceptação da chuva. 
Quadro 2. Valores de erodibilidade de um Argissolo Vermelho-Amarelo em Seropédica, RJ, no período de 2006 a 2011, em razão do $\mathrm{EI}_{30}$ e da perda de solo

\begin{tabular}{|c|c|c|c|c|c|}
\hline \multirow{3}{*}{ Período } & \multicolumn{4}{|c|}{ Índice de erodibilidade } & \multirow{3}{*}{ Número de eventos } \\
\hline & \multicolumn{2}{|c|}{ Calculado } & \multicolumn{2}{|c|}{ Estimado } & \\
\hline & $\mathbf{K a}$ & $\mathbf{K t}$ & Kei & Ket & \\
\hline & & & $\mathrm{Mg}$ ha h ha ${ }^{-1} \mathrm{MJ}^{-1} \mathrm{~mm}$ & & \\
\hline $2006-2007$ & 0,0033 & & $0,0050\left(\mathrm{R}^{2}=0,74^{* *}\right)$ & & 19 \\
\hline $2007-2008$ & 0,0076 & & $0,0078\left(R^{2}=0,72^{* *}\right)$ & & 24 \\
\hline $2008-2009$ & 0,0219 & 0,0090 & $0,0217\left(\mathrm{R}^{2}=0,70^{* * *}\right)$ & $0,0106\left(R^{2}=0,39^{* *}\right)$ & 35 \\
\hline $2009-2010$ & 0,0018 & & $0,0018\left(\mathrm{R}^{2}=0,49^{* *}\right)$ & & 14 \\
\hline $2010-2011$ & 0,0013 & & $0,0013\left(\mathrm{R}^{2}=0,72^{* *}\right)$ & & 22 \\
\hline
\end{tabular}

*** Estatisticamente significativo a $1 \%$.

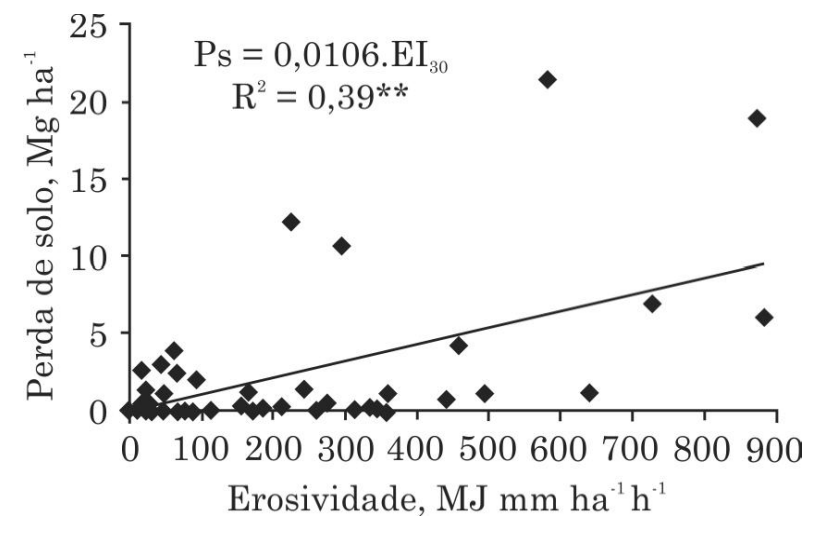

Figura 1. Dispersão e ajuste dos dados entre perda de solo e erosividade $\left(\mathrm{EI}_{30}\right)$ no período2006-2011, considerando 114 eventos individuais de chuvas erosivas. ${ }^{* *}$ Estatisticamente significativo a $1 \%$.

De acordo com Bertol et al. (2002a), é esperado que tanto os valores de RPS quanto os do fator C diminuam, à medida que a cultura se desenvolve, aumentando a cobertura e protegendo a estrutura do solo.

Segundo Pruski (2009b), quanto mais protegida pela cobertura vegetal estiver a superfície do solo contra a ação da chuva, menor será a sua propensão à ocorrência de erosão, porque, além de aumentar a quantidade de água interceptada, a vegetação tende a minimizar o efeito da energia de impacto das gotas de chuva, reduzindo a destruição dos agregados e a obstrução dos poros e o selamento superficial do solo. Além disso, a vegetação e os resíduos vegetais funcionam como obstáculos ao escoamento de excedentes hídricos, diminuindo o volume e a velocidade da enxurrada (Martins et al., 2010).

Analisando o fator $\mathrm{C}$ nas fases da cultura, observouse que os valores variaram de 0,0033 a 0,0660 , de 0,0003 a 0,0038 , de 0,0004 a 0,0018 e de 0,0000 a $0,0007 \mathrm{Mg}$ ha $\mathrm{Mg}^{-1} \mathrm{ha}^{-1}$, para as fases $1,2,3 \mathrm{e} \mathrm{4,}$ respectivamente. Segundo Gilles et al. (2009), os métodos de preparo do solo variam com a extensão de superfície do terreno trabalhada, em profundidade de preparo e em grau de fragmentação da massa de solo mobilizada. Volk et al. (2004) ressaltaram que práticas diferenciadas de manejo resultam em condições físicas de superfície e subsuperfície do solo distintas, que resultam em níveis variados de erosão hídrica.

De Maria \& Lombardi Neto (1997) obtiveram, para a cultura do milho, valores de fator $\mathrm{C}$ variando de 0,025 a $0,156 \mathrm{Mg}$ ha $\mathrm{Mg}^{-1} \mathrm{ha}^{-1}$, para os diferentes sistemas de manejo e condições edafoclimáticas. Bertol et al. (2001) obtiveram fator $\mathrm{C}$ variando de $0,0455 \mathrm{a}$ 0,1437 e de 0,0588 a $0,2158 \mathrm{Mg}$ ha $\mathrm{Mg}^{-1} \mathrm{ha}^{-1}$, para a sucessão soja e trigo, respectivamente, dependendo do sistema de manejo do solo.

Nos três ciclos de cultivo, o valor médio de RPS foi de 0,0157 e o do fator $C$ nesse mesmo período foi de 0,0070. Bertol et al. (2002a) encontraram valores médios de RPS para o milho de 0,1189; 0,0888; e 0,0611 $\mathrm{Mg}$ ha $\mathrm{Mg}^{-1} \mathrm{ha}^{-1}$, para o sistema com aração e duas gradagens;escarificação e uma gradagem; e semeadura direta, respectivamente. Nesses mesmos sistemas, os valores médios do fator $\mathrm{C}$ foram de 0,1097; 0,0809; $\mathrm{e}$ $0,0610 \mathrm{Mg}$ ha $\mathrm{Mg}^{-1} \mathrm{ha}^{-1}$, respectivamente. Verificase, portanto, que os valores obtidos por Bertol et al. (2002a) foram superiores aos encontrados neste estudo, indicando a influência do manejo e do tipo de solo na variação do fator $\mathrm{C}$.

Os valores de erosividade também apresentaram grande variação entre os anos em todos os estádios, corroborando com os dados apresentados por De Maria \& Lombardi Neto (1997), Bertolet al. (2001; 2002a).

Noquadro 4, observa-se ampla variação nos valores das perdas de solo nos dois cultivos, sendo as maiores sempre na parcela com o cultivo do milho morro abaixo. Nota-se que na fase inicial do ciclo as perdas de solo são as maiores, indicando estar relacionada a pouca cobertura do solo no estabelecimento da cultura. Essa variação explica os maiores valores do fator $\mathrm{P}$ no início do cultivo, decrescendo com o fim do ciclo da cultura. 
No primeiro período de estudo (2007/2008), verificou-se valor médiode $\mathrm{P}$ de 0,52 , indicando que a parcela $\mathrm{MN}$ reduziu em $48 \%$ as perdas de solo, em relação ao MMA. No período seguinte (2008/2009), o valor médio foi de 0,29 , o que evidenciou redução de perda na parcela MN de $71 \%$, em relação ao MMA.
Já no último período (2010/2011), o fator P foi de 0,55, constatando-se diminuição de $45 \%$ na perda de solo do MN, em relação ao MMA. Em média, foi obtido fator $\mathrm{P}$ para o MN de 0,45 , valor que expressa o efeito da disposição das linhas de plantio no controle da erosão. Segundo Bertoni\& Lombardi Neto (2010), o

Quadro 3. Valores de perdas de solo na parcela-padrão (SN), fração do $\mathrm{EI}_{30}\left(\mathrm{FEI}_{30}\right)$, razão de perdas de solo (RPS) e fator $\mathrm{C}$ nas diferentes fases da cultura do milho em nível (MN), em três ciclos de cultivos

\begin{tabular}{|c|c|c|c|c|c|}
\hline Ciclo da cultura & Fase & SN & $\mathrm{FEI}_{30}{ }^{(1)}$ & RPS & $\mathbf{C}$ \\
\hline & & $\mathrm{kg} \mathrm{ha}^{-1}$ & 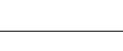 & ha $\mathrm{Mg}^{-1}$ & \\
\hline $27 / 11 / 2007$ & 1 & $4.645,85$ & 0,5948 & 0,0068 & 0,0041 \\
\hline a & 2 & 155,11 & 0,1051 & 0,0033 & 0,0003 \\
\hline \multirow[t]{3}{*}{$30 / 03 / 2008$} & 3 & $2.672,15$ & 0,2745 & 0,0014 & 0,0004 \\
\hline & 4 & $1.305,24$ & 0,0256 & 0,0004 & 0,0000 \\
\hline & Média & $2.194,59$ & 0,2500 & 0,0030 & 0,0012 \\
\hline $10 / 12 / 2008$ & 1 & $25.773,0$ & 0,3544 & 0,0093 & 0,0033 \\
\hline $\mathrm{a}$ & 2 & $12.410,0$ & 0,3172 & 0,0069 & 0,0022 \\
\hline \multirow[t]{3}{*}{$26 / 04 / 2009$} & 3 & $44.679,0$ & 0,2964 & 0,0024 & 0,0007 \\
\hline & 4 & $3.389,7$ & 0,0319 & 0,0003 & 0,0000 \\
\hline & Média & $21.562,93$ & 0,2500 & 0,0047 & 0,0016 \\
\hline 03/10/2010 & 1 & $1.434,1$ & 0,5589 & 0,1181 & 0,0660 \\
\hline $\mathrm{a}$ & 2 & 343,6 & 0,2388 & 0,0157 & 0,0038 \\
\hline \multirow[t]{3}{*}{ 06/04/2011 } & 3 & 394,6 & 0,1245 & 0,0147 & 0,0018 \\
\hline & 4 & 80,9 & 0,0778 & 0,0087 & 0,0007 \\
\hline & Média & 563,3 & 0,2500 & 0,0393 & 0,0181 \\
\hline \multicolumn{2}{|c|}{ Média dos três ciclos } & $8.106,94$ & 0,2500 & 0,0157 & 0,0070 \\
\hline
\end{tabular}

${ }^{(1)} \mathrm{FEI}_{30}$ : fração do índice de erosividade $\mathrm{EI}_{30}$, na respectiva fase da cultura.

Quadro 4. Valores de perdas de solo na parcela cultivada com milho em nível (MN) e milho cultivado morro abaixo (MMA), fator $P$ para o MN nas diferentes fases da cultura, em três ciclos de cultivos

\begin{tabular}{|c|c|c|c|c|}
\hline \multirow{2}{*}{ Ciclo da cultura } & \multirow{2}{*}{ Fase } & \multicolumn{2}{|c|}{ Perda de solo } & \multirow{2}{*}{ Fator $\mathbf{P}$} \\
\hline & & MN & MMA & \\
\hline & & 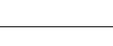 & 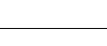 & \\
\hline $27 / 11 / 2007$ & 1 & 0,0317 & 0,0448 & 0,71 \\
\hline $\mathrm{a}$ & 2 & 0,0005 & 0,0045 & 0,11 \\
\hline \multirow[t]{3}{*}{$30 / 03 / 2008$} & 3 & 0,0038 & 0,0177 & 0,21 \\
\hline & 4 & 0,0006 & 0,0034 & 0,17 \\
\hline & Total & 0,0366 & 0,0703 & 0,52 \\
\hline $10 / 12 / 2008$ & 1 & 0,2395 & 0,6133 & 0,39 \\
\hline $\mathrm{a}$ & 2 & 0,0859 & 0,2122 & 0,40 \\
\hline \multirow[t]{3}{*}{$26 / 04 / 2009$} & 3 & 0,1079 & 0,6796 & 0,16 \\
\hline & 4 & 0,0010 & 0,0038 & 0,26 \\
\hline & Total & 0,4343 & 1,5089 & 0,29 \\
\hline 03/10/2010 & 1 & 0,1694 & 0,3049 & 0,56 \\
\hline $\mathrm{a}$ & 2 & 0,0054 & 0,0077 & 0,70 \\
\hline \multirow[t]{3}{*}{ 06/04/2011 } & 3 & 0,0058 & 0,0159 & 0,36 \\
\hline & 4 & 0,0007 & 0,0019 & 0,36 \\
\hline & Total & 0,1813 & 0,3305 & 0,55 \\
\hline \multicolumn{2}{|c|}{ Média dos três ciclos } & 0,2174 & 0,6366 & 0,45 \\
\hline
\end{tabular}


cultivo em nível pode reduzir em até $50 \%$ as perdas de solo em relação ao cultivo morro abaixo, corroborando com os dados citados anteriormente. Albuquerque et al. (2005) estudaram o efeito de práticas conservacionistas na cultura da palma e encontraram o valor do fator $\mathrm{P}$ de 0,46 , para o cultivo em nível, valor semelhante ao encontrado neste estudo.

\section{CONCLUSÕES}

1. As erodibilidades do solo estudado conseguida pelo quociente entre perdas de solo e erosividade (Kt) nos cinco anos de pesquisafoi de $0,0090 \mathrm{Mg}$ ha h ha-1 $\mathrm{MJ}^{-1} \mathrm{~mm}^{-1}$ e de $0,0106 \mathrm{Mg}$ ha h ha ${ }^{-1} \mathrm{MJ}^{-1} \mathrm{~mm}^{-1}$, obtidas pelo método da regressão (Kct), podendo ser usadas como primeira aproximação.

2. O valor médio do fator $\mathrm{C}$ calculado é de 0,0070 $\mathrm{Mg}$ ha $\mathrm{Mg}^{-1} \mathrm{ha}^{-1}$ para a cultura do milho cultivado em nível (MN).

3. $O$ valor médio do fator $P$ para o milho cultivado em nível é de 0,45 , indicando redução de $55 \%$ na perda de solo do MN, em relação ao MMA.

\section{AGRADECIMENTOS}

Ao Curso de Pós-Graduação em Agronomia-Ciência do Solo da UFRRJ; à Capes e FAPERJ, pela bolsa de estudo; aos funcionários da Embrapa-Agrobiologia, pelo auxílio na condução do experimento.

\section{LITERATURA CITADA}

ALBUQUERQUE, A.W.; FILHO, G.M.; SANTOS, J.R.; COSTA, J.P.V. \& SOUZA, J.L. Determinação de fatores da equação universal de perda de solo em Sumé, PB. R. Bras. Eng. Agríc. Amb., 9:153-160, 2005

AMARAL, A.J.; BERTOL, I.; COGO, N.P. \& BARBOSA, F.T. Redução da erosão hídrica em três sistemas de manejo do solo em um Cambissolo Húmico da região do planalto sul - catarinense. R. Bras. Ci. Solo, 32:2145-2155, 2008.

AMORIM, R.S.S.; SILVA, D.D.; PRUSKI, F.F. \& MATOS, A.T. Avaliação do desempenho dos modelos de predição da erosão hídrica USLE, RUSLE E WEPP para diferentes condições edafoclimáticas do Brasil.Eng. Agríc., 30:1046-1049, 2010.

AMORIM, R.S.S.; SILVA, D.D. \& PRUSKI, F.F. Principais modelos para estimar as perdas de solo em áreas agrícolas. In: PRUSKI, F.F., ed. Conservação de solo e água: Práticas mecânicas para o controle da erosão hídrica. 2.ed. Viçosa, MG, Universidade Federal de Viçosa, 2009. p.74-107.
BERTOL，I.;LEITE，D.; ENGEL，F.L.; COGO，N.P.\& GONZÁLEZ, A.P. Erodibilidade de um NitossoloHáplicoalumínico determinada em condições de campo. R. Bras. Ci. Solo, 31:541-549, 2007.

BERTOL, I.; SCHICK, J. \& BATISTELA, O.Razão de perdas de solo e fator C para as culturas de soja e trigo em três sistemas de preparo em um Cambissolo Húmico alumínico. R. Bras. Ci. Solo, 25:451-461, 2001.

BERTOL, I.; SCHICK, J. \& BATISTELA, O.Razão de perdas de solo e fator C para milho e aveia em rotação com outras culturas em três tipos de preparo de solo. R. Bras. Ci. Solo, 26:545-552, 2002a.

BERTOL, I.; SCHICK, J.; BATISTELA, O.; LEITE, D. \& AMARAL, A.J. Erodibilidade de um Cambissolo Húmico alumínicoléptico, determinada sob chuva natural entre 1989 e 1998 em Lages (SC). R. Bras. Ci. Solo, 26:465-471, 2002b.

BERTONI, J. \& LOMBARDI NETO, F. Conservação do solo. 7.ed. São Paulo, Ícone, 2010. 355p.

CARVALHO, D.F.; CRUZ, E.S.; PINTO, M.F.; SILVA, L.D.B. \& GUERRA, J.G.M. Características da chuva e perdas por erosão sob diferentes práticas de manejo do solo. R. Bras. Eng. Agríc. Amb., 13:3-9, 2009.

CARVALHO, D.F.; MONTEBELLER, C.A.; FRANCO, E.M.; VALCARCEL, R. \& BERTOL, I. Padrões de precipitação e índices de erosividade para as chuvas de Seropédica e Nova Friburgo - RJ. R. Bras. Eng. Agríc. Amb., 9:7-14, 2005.

De MARIA, I.C. \& LOMBARDI NETO, F. Razão de perdas de solo e fator C para sistemas de manejo da cultura do milho. R. Bras. Ci. Solo, 21:263-270, 1997.

DENARDIN, J.E. Erodibilidade de solo estimada por meio de parâmetros físicos e químicos. Piracicaba, Escola Superior de Agricultura Luiz de Queiroz, 1990. 81p. (Tese de Doutorado)

EDUARDO, E.N. Determinação da erodibilidade e do fator cobertura e manejo do solo sob condições de chuva natural e simulada. Seropédica, Universidade Federal do Rio de Janeiro, 2012. 56p. (Dissertação de Mestrado)

EMPRESA BRASILEIRA DE PESQUISA AGROPECUÁRIA EMBRAPA. Manual de métodos de análise de solo. 2.ed. Rio de Janeiro, 1997. 212p.

FOSTER, G.R.; MCCOOL, D.K.; RENARD, K.G.\& MOLDENHAEUR, W.C. Conversion of the universal soil loss equation to si units. J. Soil Water Conserv., 36:335359, 1981.

FRAUENFELD, B. \& TRUMAN, C.C. Variable rainfall intensity effects on runoff and interrill erosion from two Coastal Plain Utlisols in Georgia. Soil Sci., 169:143-154, 2004.

GILLES, L.; COGO, N.P.; BISSANI, C.A.; BAGATINI, T. \& PORTELA, J.C. Perdas de água, solo, matéria orgânica e nutriente por erosão hídrica na cultura do milho implantada em área de campo nativo, influenciadas por métodos de preparo do solo e tipos de adubação. R. Bras. Ci. Solo, 33:1427-1440, 2009. 
KINNELL, P.I.A. Event soil loss, runoff and the universal soil loss Equation family of models: A review. J. Hydrol., 385:384-397, 2010.

MARQUES, J.J.G.S.M.; ALVARENGA, R.C.; CURI, N.; SANTANA, D.P. \& SILVA, M.L.N. Índices de erosividade da chuva, perdas de solo e fator erodibilidade para dois solos da região dos cerrados - primeira aproximação. R. Bras. Ci. Solo, 21:427-434, 1997.

MARTINS, S.G.; SILVA, M.L.N.; AVANZI, J.C.; CURI, N. \& FONSECA, S. Fator cobertura e manejo do solo e perdas de solo e água em cultivo de eucalipto e em Mata Atlântica nos Tabuleiros Costeiros do estado do Espírito Santo. Sci. For., 38:517-526, 2010.

MORGAN, R.P.C. Soil erosion \& conservation. 3.ed. New York, Longman Scientific \& Technical, 2005. 304p.

PRUSKI, F.F. Fatores que interferem na erosão hídrica do solo. In: PRUSKI, F.F., ed. Conservação de solo e água: Práticas mecânicas para o controle da erosão hídrica.2.ed. Viçosa, MG, Universidade Federal de Viçosa, 2009a. p.41-74.

PRUSKI, F.F. Processo físico de ocorrência da erosão hídrica. In: PRUSKI, F.F., ed. Conservação de solo e água: Práticas mecânicas para o controle da erosão hídrica. 2.ed. Viçosa, MG, Universidade Federal de Viçosa, 2009b. p.24-39.
SILVA, A.M.; SILVA, M.L.N.; CURI, N.; AVANZI, J.C. \& FERREIRA, M.M. Erosividade da chuva e erodibilidade de Cambissolo e Latossolo na região de Lavras, sul de Minas Gerais. R. Bras. Ci. Solo, 33:1811-1820, 2009.

SILVA, M.L.N.; CURI, N.; LIMA, J.M. \& FERREIRA, M.M. Avaliação de métodos indiretos de determinação da erodibilidade de Latossolos brasileiros. Pesq. Agropec. Bras., 35:1207-1220, 2000.

SINGH, M.J. \& KHERA, K.L. Nomographic estimation and evaluation of soil erodibility under simulated and natural rainfall conditions. Land. Degrad. Develop., 20:471-480, 2009.

VOLK, L.B.S.; COGO, N.P. \& STRECK, E.V. Erosão hídrica influenciada por condições físicas de superfície e subsuperfície do solo resultantes do seu manejo, na ausência de cobertura vegetal. R. Bras. Ci. Solo, 28:763$774,2004$.

WISCHMEIER, W.H.; JOHNSON, C.B. \& CROSS, B.V. A soil erodibility nomograph for farmland and construction sites. J. Soil Water Conserv., 26:189-193, 1971.

WISCHMEIER, W.H. Cropping-management factor for a universal soil-loss equation. Soil Sci. Soc. Am. Proc., 24:322-326, 1960.

WISCHMEIER, W.H. \& SMITH, D.D. Predicting rainfall erosion losses: A guide to conservation planning. Washington, USDA, 1978. 58p. (Agriculture Handbook, 5) 